\section{The metal post material influences the performance of artefact reduction algorithms in $\mathrm{CBCT}$ images}

\author{
Amanda Farias-Gomes (D1, Rocharles Cavalcante Fontenele (D1, Lucas \\ P. Lopes Rosado (1)1, Frederico Sampaio Neves (1)1,2, Deborah Queiroz \\ Freitas (101.
}

\begin{abstract}
${ }^{1}$ Department of Oral Diagnosis, Division of Oral Radiology, Piracicaba Dental School, University of Campinas, Piracicaba, SP, Brazil

\footnotetext{
2 Department of Propedeutics and Integrated Clinic, Division of Oral Radiology, School of Dentistry, Federal University of Bahia, Salvador BA, Brazil.
}

Correspondence: Amanda Farias Gomes Postdoctoral Researcher, University of Campinas. Piracicaba Dental School, Department of Oral Diagnosis. Av. Limeira, 901, Zip Code 13414-903, Piracicaba, Sao Paulo, Brazil. Phone: +55 1921065227.

E-mail: aamandafg@outlook.com
Key Words: Artefacts, conebeam computed tomography, endodontics, metals.

\title{
Introduction
}

Cone beam computed tomography (CBCT) has allowed great advances in diagnosis and planning in Dentistry due to its three-dimensional nature, with the representation of maxillofacial structures without image overlapping (1). Nevertheless, one of its greatest disadvantages is the formation of artefacts, which impair image quality and can hamper the recognition of several alterations and diseases. Amid the variety of artefacts in CBCT, those originating from the hardening of the X-ray beam, caused by materials of high atomic number and high-density, such as metal posts, may critically impact diagnoses of endodontic interest $(2,3)$.

Prior researches have demonstrated a decrease in diagnostic values, specially of root fractures, when intracanal materials were present in the evaluated tooth $(2,4,5)$. Such finding is probably related to the fact that the beam-hardening artefacts are depicted in the image as hyperdense bands, which may cover a fracture line, and as hypodense bands, which may simulate the presence of a root fracture $(3,6,7)$. Moreover, it has been shown that the expression (hypodense or hyperdense) of the artefact in a tooth varies according to the intracanal material, the tooth position in the dental arch (anterior or posterior), and CBCT machine used (8).

Due to the negative impact of image artefacts, several studies have attempted to decrease or eliminate them by testing pre- (tube current, kilovoltage, number of basis images, voxel size, and field of view - FOV) and post-acquisition (metal artefact reduction - MAR - algorithms) variables (3,8-11). The MAR tool corresponds to algorithms developed by producers of some CBCT to enhance image quality throughout the reconstruction process, decreasing beam-hardening artefacts. It stands out in 
relation to the other variables, as it reduces the variance of gray values and elevates the contrast-tonoise ratio in the images without influencing the dose of radiation delivered to the patient $(10,12)$.

Despite the effectiveness of MAR in improving image quality objectively, there is controversy regarding its efficacy on the diagnosis, since its use has demonstrated little or no effect on the diagnosis of various clinical conditions, e.g. periodontal defects, fractured endodontic tools, and root fractures (7,13-16). According to the consulted literature, the studies that objectively assessed the performance of the MAR tool have conducted such analyses on acrylic phantoms $(10,17,18)$ or in regions not corresponding to the teeth $(12,19)$. Therefore, it would be of interest to comprehend the effect of the MAR tool on different regions of the tooth to elucidate why these algorithms have demonstrated a positive effect on the objective image quality, but not on diagnosis. Additionally, it would be important to understand the influence of different metal post materials and regions of the dental arch on the MAR performance. Thus, the aim in this study was to assess the effect of the MAR tool on the expression of artefacts in different regions of a tooth restored with different types of metal posts, in CBCT images.

\section{Material and methods}

This research was conducted after approval by the local research ethics committee (protocol CAAE 29004820.9.0000.5418).

The sample size was calculated in the Biostat software (version 5.3, Instituto de Desenvolvimento Sustentável Mamirauá, Tefé, MA, Brazil) and was based on the minimum difference among the groups, and the mean SD, adopting a statistical power of 0.75 . Thus, the study sample was composed of three CBCT scans per group.

\section{Sample preparation}

The research sample consisted of one single-rooted human tooth, and one edentulous dry human mandible. The tooth was cleaned with 70\% alcohol, had calculi and soft tissue residue removed by ultrasonic scaling, and went through clinical and radiographic evaluation to verify the absence of root fractures, resorptive lesions, canal treatment, calcification, open apex, and dental anomalies. Then, with a diamond disc saw (Isomet 1000, Buehler Ltd., Lake Bluff, USA), the crown was sectioned at the cementoenamel junction.

Then, the root canal was instrumented to its entire length with a Mtwo NiTi rotatory system (VDW GmbH, Munich, Germany), using the protocol (size/taper) 10/0.04, 15/0.05, 20/0.06, and 25/0.06, and irrigation with distilled water (8). Posteriorly, the first two-thirds of the root were assessed with a number 2 piezo drill (Peeso Long Drill, Dentsply Sirona, Canada) for metal post placing. The metal posts - cobalt-chromium (Co-Cr), nickel-chromium ( $\mathrm{Ni}-\mathrm{Cr}$ ), and silver-palladium ( $\mathrm{Ag}-\mathrm{Pd}$ ) - were made by molding the root canal with a regular pin of Duralay acrylic resin. All metal posts had the same thickness and length $(20 \mathrm{~mm})$.

The dry mandible was used as a phantom for tooth accommodation. To do so, two alveolar sockets (right central incisor, and right first molar) were enlarged with a \#1016 round diamond bur (KG Sorensen, Brazil) to fit the tooth passively. Previously to the CBCT scanning, the mandible was attached to the bottom of a plastic canister $(16 \mathrm{~cm}$ diameter) filled with water. The water was employed to mimic the attenuation of X-rays by the soft tissues (8). At distinct times, the tooth was placed into the enlarged alveolar sockets to obtain the CBCT images.

\section{Image acquisitions}

All scans were acquired with an OP300 Maxio (Instrumentarium Dental, Tuusula, Finland) device set at: $0.2 \mathrm{~mm}$ voxel size, $8 \times 6 \mathrm{~cm}$ FOV, $90 \mathrm{kVp}, 5 \mathrm{~mA}, 17.4 \mathrm{~s}$ scanning time, and 234 frames.

The plastic canister containing the set "mandible + tooth" was fixed in the platform of the CBCT unit, and the position of the mandible was standardized by the reference lights of the machine. For each region of the mandible (anterior and posterior) and condition of MAR (enabled and disabled), four image sets were obtained according to the studied metal post. At first, scans of the tooth without the post placed inside the root canal (control group) were obtained. After, scans of the groups - $\mathrm{Ni}-\mathrm{Cr}$, $\mathrm{Co}-\mathrm{Cr}$, and $\mathrm{Ag}-\mathrm{Pd}$ posts - were acquired (Figure 1). The posts were passively and individually placed inside the root canal, and all scans were obtained without stirring the phantom from its initial location in the machine. Each protocol was replicated 03 times for reproducibility, resulting in $48 \mathrm{CBCT}$ images 
(4 tested groups $\times 2$ mandibular regions $\times 2$ conditions of MAR $\times 3$ repetitions). During the image acquisitions, the phantom and the platform of the CBCT unit remained static to assure standardization of the position of the phantom during all scans. The MAR tool was applied for each scan, individually, right after obtaining the image with the "without MAR" protocol, without the need to acquire a new scan. The OP300 Maxio CBCT unit have two modes of MAR tool activation: one allows acquiring the scan with the MAR activated, and the other to acquire the scan without the MAR and then retrieve it with the MAR activated, with identical effects on the image (19).

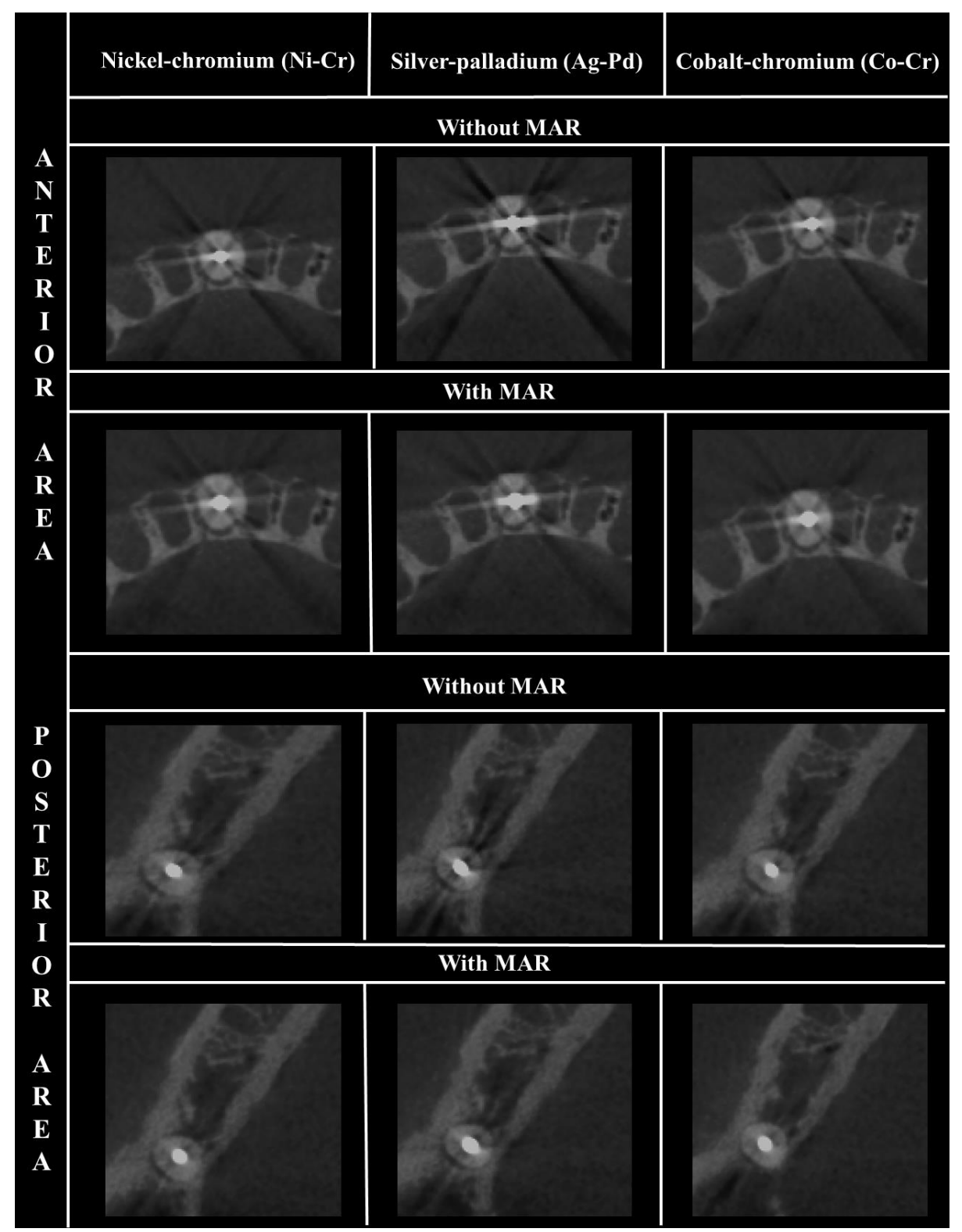

Figure 1. Cropped CBCT reconstructions (axial view) of each metal post (nickel-chromium, silverpalladium, and cobalt-chromium posts) tested, according to the MAR mode (with or without activation) and mandibular region.

\section{Image assessment}

Images were exported as 8-bits TIFF files to the Image J software v.1.51 (National Institutes of Health, Bethesda, USA). They were individually assessed by an oral radiologist experienced in the objective assessment of image quality, in a calm and dark room.

For analysis, the methodology established by Fontenele et al. was followed (8). Summarizing, the axial reconstruction at the middle level of the root was chosen for each CBCT scan. To do so, the first and last axial reconstructions in which the root was observed were used as guidance. On each 
middle level scan, 08 lines of interest (LOIs) (1.3mm-length, each) were demarcated around the root canal: 04 lines in oblique orientations (mesiolingual, distolingual, mesiobuccal, and distobuccal) and 04 lines in orthogonal directions (mesial, distal, buccal, and lingual), propagating from the outer surface of the post / root canal (control group) to the outer surface of the root (Figure $2 \mathrm{C}$ and 2F).
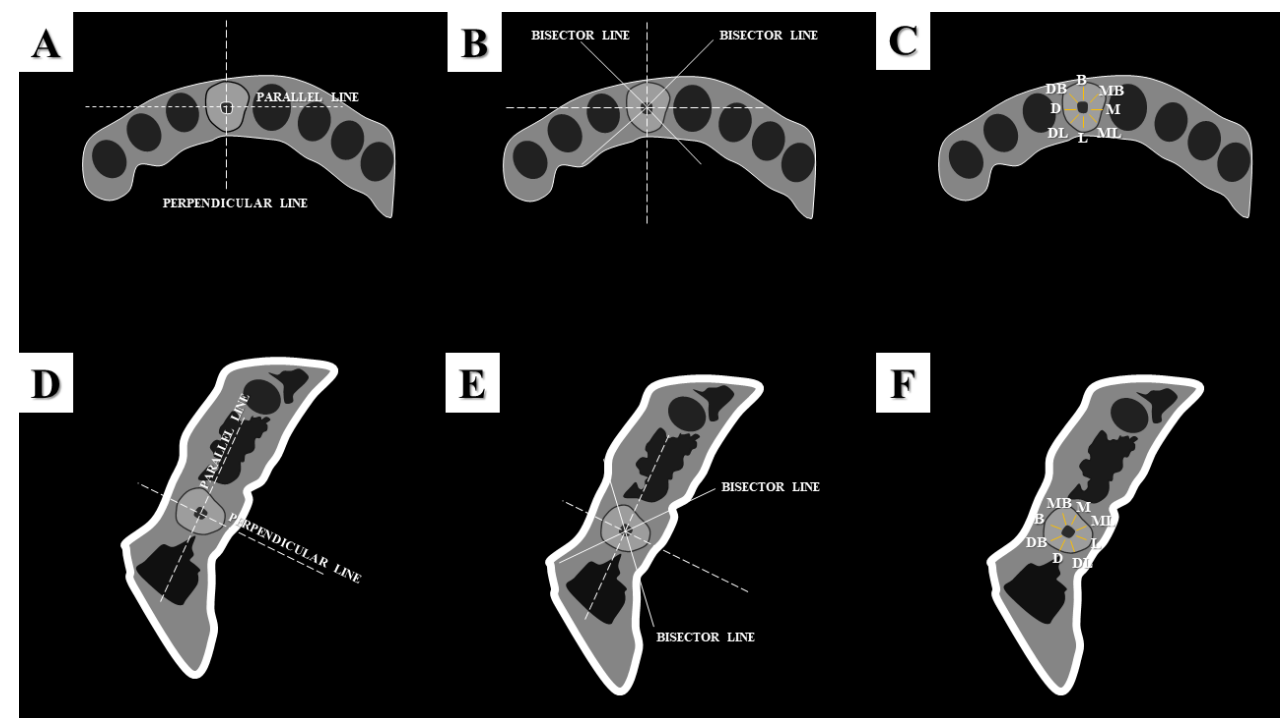

Figure 2. Schematic representation of the objective analysis according to the region of the mandible (anterior or posterior). (A-D) First, for each CBCT scan, the axial reconstruction at the middle level of the root was selected. Two lines were determined: one line crossing the center of the root canal, following the mandible's long axis, and a line perpendicular to the first one. (B-E) At the intersection of the previously determined lines, two bisector lines $\left(45^{\circ}\right)$ were drawn. Eight LOls $(1.3 \mathrm{~mm}$-length, each) were set on the perpendicular, parallel and bisector lines: four LOls were established in the orthogonal orientations (buccal, lingual, mesial and distal regions of the root), and four LOls were established in the oblique directions (mesiobuccal, distobuccal, mesiolingual and distolingual regions of the root). LOls, Lines of interest.

To establish the LOIs, a line crossing the center of the root canal, and parallel to the mandible's long axis, was drawn. Then, it was established a line perpendicular to the first one (Figure 2A-2D); at the encounter of these lines, 02 bisectorial lines $\left(45^{\circ}\right)$ were traced (Figure $2 \mathrm{~B}-2 \mathrm{E}$ ). The orthogonal LOIs were demarcated around the root canal, on the perpendicular and parallel lines, while the oblique LOls were demarcated on the bisecting lines (Figure $2 \mathrm{C}$ and $2 \mathrm{~F}$ ). For every LOI, it was assessed the mean of the gray values. The beam-hardening artefacts expression was obtained by calculating the difference in the mean of gray values (DMGV) between the experimental groups (with metal post) and the control group (without metal post) for each LOI, within each post material. Thus, positive DMGV meant hyperdense artefacts, whereas negative DMGV meant hypodense artefacts. To standardize the establishment of the LOIs in the different scans, it was used the MACRO function of the ImageJ software. Also, the DMGV was acquired in a standardized manner, since both images, with and without MAR activation, were obtained without displacing the phantom from its initial spot in the CBCT unit. One-hundred and twenty days after the end of the image evaluation, the same evaluator assessed all CBTC scans and performed a new evaluation following the methodology previously described, to calculate the intra-examiner agreement.

\section{Statistical analysis}

The intra-examiner agreement was calculated by the intraclass correlation coefficient (ICC) and interpreted according to the Cicchetti classification (20). Analysis of variance (multi-way ANOVA) with post-hoc Tukey's test compared the DMGV to assess the effect of MAR also considering the other conditions that varied (post material and mandibular region) and their interactions. The null hypothesis assumed that the factors do not have an effect on the beam-hardening artefacts expression. Data were analyzed with the GraphPad Prism software v.7.0 (GraphPad Software, La Jolla, USA) and SPSS software v.24.0 (IBM Corp., Armonk, USA), with a significance level of $5 \%$ (p-value < 0.05 ). 


\section{Results}

The ICC value was 0.99, showing an excellent intra-examiner agreement. Table 1 demonstrates the DMGV between the test (metal post) and control (without metal post) groups according to post material, artefact direction, mandibular region, and MAR condition.

For the Ni-Cr group, there was no significant difference between the "without MAR" and "with MAR" conditions for any direction, in neither the anterior nor posterior regions of the mandible ( $p>0.05)$, except for the mesial direction in the posterior region $(p<0.05)$. A comparable trend was observed for the $\mathrm{Co}-\mathrm{Cr}$ group, in which there were no significant differences between the "without MAR" and "with MAR" settings for most conditions ( $p>0.05$ ), except for the buccal and distobuccal directions in the anterior region of the mandible $(p<0.05)$. On the other hand, for the Ag-Pd post, significant differences were observed between "without MAR" and "with MAR" in most directions, in both the anterior (lingual, mesiobuccal, distobuccal, mesiolingual, distolingual) and posterior (mesial, distal, mesiobuccal, and distolingual) regions of the mandible $(p<0.05)$. In general, when MAR was effective, there was a homogenization in the gray values, since for positive DMGV, there was a decrease in the mean of gray values, while for negative DMGV, there was an increase in the mean of gray values. It was observed that the MAR tool acted mostly in hypodense artefacts, except for two cases (lingual direction - anterior region of the mandible - in the Ag-Pd group, and in the buccal direction - anterior region of the mandible - in the Co-Cr group).

Table 1. Difference of the mean of gray values (DMGV) between the test (metal posts) and control (without metal post) groups according to the post material, mandibular region, artefact direction, and metal artefact reduction (MAR) condition.

\begin{tabular}{|c|c|c|c|c|c|c|c|}
\hline & \multirow[b]{3}{*}{ Direction } & \multicolumn{6}{|c|}{ Mean of DMGV (Standard deviation) } \\
\hline & & \multicolumn{2}{|c|}{$\mathrm{Ni}-\mathrm{Cr}$} & \multicolumn{2}{|c|}{$\mathrm{Ag}-\mathrm{Pd}$} & \multicolumn{2}{|c|}{$\mathrm{Co}-\mathrm{Cr}$} \\
\hline & & Without MAR & With MAR & Without MAR & With MAR & Without MAR & With MAR \\
\hline \multirow{8}{*}{$\begin{array}{l}\text { Anterior } \\
\text { region }\end{array}$} & Buccal & $3.04(3.65)$ & $2.72(3.53)$ & $9.30(2.63)$ & $11.12(1.94)$ & $26.48(30.10)$ & $12.80(0.12)^{*}$ \\
\hline & Lingual & $15.51(1.37)$ & $13.22(0.92)$ & $17.23(2.17)$ & $4.55(3.99)^{*}$ & $9.26(1.17)$ & $7.23(1.11)$ \\
\hline & Mesial & $44.57(5.46)$ & $40.01(4.99)$ & $55.47(4.44)$ & $55.97(1.25)$ & $44.82(0.50)$ & $38.96(1.91)$ \\
\hline & Distal & $64.88(6.79)$ & $59.66(6.87)$ & $74.85(2.88)$ & $73.89(2.84)$ & $70.05(1.83)$ & $65.16(1.64)$ \\
\hline & Mesiobuccal & $-19.37(5.11)$ & $-15.44(4.34)$ & $-27.92(2.06)$ & $1.36(3.40)^{*}$ & $11.88(1.90)$ & $13.82(1.97)$ \\
\hline & Distobuccal & $-29.23(2.96)$ & $-17.59(1.23)$ & $-32.43(3.87)$ & $-0.49(2.30)^{*}$ & $-23.26(0.26)$ & $-8.15(2.05)^{*}$ \\
\hline & Mesiolingual & $-33.36(0.43)$ & $-26.76(2.59)$ & $-40.64(2.55)$ & $-24.00(3.36)^{*}$ & $-30.49(1.49)$ & $-24.14(2.91)$ \\
\hline & Distolingual & $-11.83(4.12)$ & $-1.00(2.75)$ & $-40.67(2.62)$ & $-13.34(6.22)^{*}$ & $-15.41(1.68)$ & $-12.61(1.91)$ \\
\hline \multirow{8}{*}{$\begin{array}{l}\text { Posterior } \\
\text { region }\end{array}$} & Buccal & $13.94(2.42)$ & $18.39(2.58)$ & $32.00(1.98)$ & $36.80(1.18)$ & $20.78(2.72)$ & $25.45(2.46)$ \\
\hline & Lingual & $26.48(1.01)$ & $26.30(1.03)$ & $51.26(2.58)$ & $46.94(1.60)$ & $26.08(2.32)$ & $25.78(1.36)$ \\
\hline & Mesial & $-16.54(2.25)$ & $-7.32(2.08)^{*}$ & $-28.54(3.46)$ & $-17.15(3.67)^{*}$ & $-18.67(1.31)$ & $-12.04(1.25)$ \\
\hline & Distal & $-4.05(1.92)$ & $-0.35(1.56)$ & $-18.35(2.98)$ & $-4.73(2.91)^{*}$ & $-3.07(1.59)$ & $2.19(0.78)$ \\
\hline & Mesiobuccal & $-5.19(5.77)$ & $-0.89(4.29)$ & $-18.90(5.66)$ & $-10.37(3.05)^{*}$ & $-8.87(4.08)$ & $-5.99(3.69)$ \\
\hline & Distobuccal & $23.12(2.80)$ & $22.37(2.21)$ & $32.79(2.30)$ & $31.96(2.65)$ & $18.67(1.02)$ & $18.32(0.75)$ \\
\hline & Mesiolingual & $38.27(1.94)$ & $37.53(1.57)$ & $43.62(4.45)$ & $40.54(4.37)$ & $30.72(2.92)$ & $31.80(2.35)$ \\
\hline & Distolingual & $-6.07(3.05)$ & $-1.40(3.18)$ & $-7.55(3.29)$ & $3.52(4.38)^{*}$ & $-1.57(2.59)$ & $2.76(2.41)$ \\
\hline
\end{tabular}

* Significantly differed from "without MAR" within the same post material, direction, and mandibular region evaluated $(p<0.05)$.

\section{Discussion}

In the present study, it was aimed to assess the effect of the MAR tool on the expression of artefacts in different regions of a tooth restored with different types of metal posts, in CBCT images. It was found that the MAR tool performed differently depending on the metal post composition. In general, when the tooth was restored with a $\mathrm{Ni}-\mathrm{Cr}$ or $\mathrm{Co}-\mathrm{Cr}$ post, MAR was not effective, since there was no significant decrease in the artefact expression in the different regions of the tooth. However, the MAR tool acted positively in regions where artefacts (hyperdense or hypodense) were more 
pronounced, i.e., when the tooth was restored with an Ag-Pd post. Therefore, these findings can shed a light on the reason why previous studies (21-25) have reported that the MAR tool is not efficient in improving the diagnosis of VRF in teeth restored with metal posts.

The beam hardening phenomenon has been extensively studied in the literature. Its effects hamper the diagnosis of different conditions in Dentistry, mainly in Endodontics and Oral Rehabilitation. In addition to impacting the diagnosis of root fractures, as previously mentioned, the beam hardening phenomenon also influences measurements around dental implants by overestimating the implant diameter (26), making it difficult to detect gaps at prosthetic crowns (27); it also decreases the detection of internal root resorptions when adjacent teeth are restored with metal posts (28), impairs the diagnosis of misfits at the implant-abutment joint (29), and hamper the diagnosis of fractured endodontic instruments in teeth filled with gutta-percha (30).

Previous researches have also objectively investigated the expression of artefacts in teeth with metal posts $(8,31,32)$; however, the methodologies used were different from that of the present study. Lira de Farias Freitas et al. (32) quantitatively evaluated the artefacts produced by two types of metal posts ( $\mathrm{Ni}-\mathrm{Cr}$ and $\mathrm{Ag}-\mathrm{Pd}$ ) by using the threshold of gray values that would best represent each type of artefact (hypodense or hyperdense). Although it is an effective analysis for the total quantification of the artefacts produced, this methodology does not allow to determine which regions of the tooth would be most affected by each type of artefact. Conversely, Fontenele et al. (8) proposed the mapping (i.e., analysis of the expression of the artefacts in different regions of the tooth) of artefacts generated by different metal posts ( $\mathrm{Ni}-\mathrm{Cr}, \mathrm{Ag}-\mathrm{Pd}$, and $\mathrm{Co}-\mathrm{Cr}$ ). They used the mean of gray values to determine which areas of the tooth were more affected by artefacts, according to their intensity (hyperdense or hypodense). The intensity of the artefacts was obtained from the comparison between a control group (without metal post) and the experimental groups (with metal posts); however, the interpretation of the generated data is not direct, which can make it difficult for clinicians to understand their results. Differently, the objective analysis employed in the present study is novel and easy for clinicians to comprehend, as it is possible to know which regions of the tooth had hypodense (negative DMGV), or hyperdense artefacts (positive DMGV), from directly reading the results.

The objective assessment of the expression of artefacts generated by high-density materials (e.g. dental implants, metal posts, amalgam, and gutta-percha) has been broadly performed in the literature $(8,10-12,17,19)$. In agreement with the present investigation, these previous studies have also made use of a single evaluator, since automated tools (e.g. MACRO and ROI manager of the ImageJ software) were used to perform the analyses. In our study, in addition to the use of the MACRO tool, the phantom and the platform of the CBCT unit remained immobile during all image acquisitions, assuring the standardization of the image analyses. Such standardization was demonstrated by the excellent values of reproducibility obtained.

The performance of the MAR algorithms has been investigated, both objectively and subjectively $(8,12,19,25)$. It is a consensus that the MAR tool promotes some homogenization in the gray values in the areas most affected by the beam-hardening artefacts in an image $(11,12,19)$. However, the MAR tool has demonstrated no effect, or even a negative influence, on several diagnostic tasks (e.g., VRF in teeth restored with metal posts) $(13,14,21-25)$, which generates controversy between the objective and subjective studies on the effect of MAR on CBCT image quality, especially with regard to the diagnosis of VRF. As far as we know, there are no studies about the influence of the MAR tool on the artefact production in different regions of a tooth restored with distinct metal posts. Our results may explain why the MAR activation does not improve the accuracy in the diagnosis of VRF in teeth with metal posts, as we found that the MAR tool is ineffective in reducing the artefacts generated by $\mathrm{Ni}-\mathrm{Cr}$ and $\mathrm{Co}-\mathrm{Cr}$ alloys. These artefact-generator materials were commonly used in experimental studies that have evaluated the influence of different acquisition parameters (e.g., MAR) on the diagnosis of $\operatorname{VRF}(3,5,14)$. Thus, in face of our results, it may be expected that there will be no enhancement in the VRF diagnosis in teeth restored with $\mathrm{Ni}-\mathrm{Cr}$ and $\mathrm{Co}-\mathrm{Cr}$ alloys when MAR is enabled.

Therefore, regarding the effect of the different post materials and the MAR performance, an interesting result was observed in our research. The MAR tool was effective in promoting some homogenization in the gray values (i.e., reducing the positive DMGV values, and increasing the negative DMGV values) in several regions of the tooth restored with an $\mathrm{Ag}-\mathrm{Pd}$ post, regardless of the mandibular region (anterior or posterior) tested. In contrast, little or no effect of MAR was observed in the $\mathrm{Ni}-\mathrm{Cr}$ and $\mathrm{Co}-\mathrm{Cr}$ groups. This different behaviour of the MAR algorithms in relation to the alloys may be 
explained by their distinct atomic numbers and physical densities. The Ag-Pd post has higher atomic number $(\mathrm{ZAg}=47$ and $\mathrm{ZPd}=46)$ than the other alloys tested $(\mathrm{ZNi}=28 ; \mathrm{ZCr}=23 ; \mathrm{ZCo}=24 ; \mathrm{ZCr}=27)$; likewise, according to the manufacturer's information, the physical density of the $\mathrm{Ag}-\mathrm{Pd}$ is higher $\left(d=10.4 \mathrm{~g} / \mathrm{cm}^{3}\right)$ than that of the Ni-Cr $\left(d=8.2 \mathrm{~g} / \mathrm{cm}^{3}\right)$ and $\mathrm{Co}-\mathrm{Cr}\left(\mathrm{d}=8.6 \mathrm{~g} / \mathrm{cm}^{3}\right)$ alloys, which leads to greater production of artefacts, due to the greater absorption of low energy X-rays, by the former material $(8,11,32)$. In line with previous studies $(12,19)$, we proved that the MAR tool performs better when there is greater production of artefacts, as observed in several regions of the tooth restored with $\mathrm{Ag}-\mathrm{Pd}$. Thus, although it was not our aim to directly compare the expression of artefacts among the post materials, the results of the present study may indicate that the choice of the metal post should not be based solely on the physicochemical properties of the material, but also on its potential to generate image artefacts and/or be positively impacted by the use of MAR. Nevertheless, further studies investigating the expression of artefacts and performance of MAR on diagnostic tasks involving teeth restored with different post materials are encouraged.

Another outcome of the present study is related to the type of artefact that was most affected by the MAR tool. Of all regions $(n=12)$ influenced by MAR activation, only two had hyperdense artefacts (positive DMGV). The other regions $(n=10)$ had hypodense artefacts (negative DMGV). Extrapolating for a clinical scenario, our results suggest that MAR would be more effective in decreasing the number of false-positive cases of VRF, as it was better in decreasing artefacts that mimic fracture lines. Conversely, MAR would not be so effective in reducing false-negative cases of VRF, as it was less effective in reducing hyperdense artefacts, which may cover fracture lines.

We recognize that the main guidelines on the applications of CBCT in endodontics $(33,34)$ recommend the use of the smallest FOV and voxel size (high-resolution) available. However, in this study, we used a medium FOV $(8 \times 6 \mathrm{~cm})$, as we needed to encompass the anterior and posterior aspects of the mandible in the same volume, even though different exams have been acquired to evaluate each region. As suggested by previous studies $(7,8,35)$, the use of a medium FOV in this type of experimental model is recommended in order to standardize the structures inside and outside the FOV, thereby, avoiding negative and varied influence of the exomass in the evaluation of the gray values in structures located inside the FOV (36). About the voxel size, we selected the smallest voxel available for the selected acquisition protocol.

The present study had an in vitro design, which has inherent limitations. However, this was the only possible method to evaluate the various factors tested, as it is ethically and biologically unacceptable to expose a patient to radiation several times only for research proposes. However, to simulate a clinical scenario as accurately as possible, the images used in the present study were acquired using a phantom composed of a human mandible and a human tooth included in a container filled with water (i.e., simulating the attenuation of the X-rays by human soft tissues). A limitation of this study is that only the MAR algorithm available in the OP300 CBCT unit was tested. This equipment was chosen as it allows to obtain a scan without the application of MAR, and another one with the MAR applied, in the same acquisition, guaranteeing that the phantom was not moved during the acquisitions, which is essential for a trustworthy objective analysis. We suggest that future studies investigate the influence of other MAR algorithms on the expression of artefacts in teeth restored with metal posts.

In conclusion, the effectiveness of the MAR tool available in the OP300 CBCT unit varied according to the post material and artefact expression. It was effective in reducing the expression of artefacts generated by the Ag-Pd post, mainly in the areas affected by hypodense artefacts, regardless of the mandibular region. The same performance was not observed for the $\mathrm{Co}-\mathrm{Cr}$ and $\mathrm{Ni}-\mathrm{Cr}$ posts.

\section{Acknowledgments}

This study was financed in part by the Coordenação de Aperfeiçoamento de Pessoal de Nivel Superior - Brasil (CAPES) - Finance Code 001. 


\section{Resumo}

0 objetivo nesse estudo foi avaliar o efeito da ferramenta de redução de artefato (FRA) na expressão de artefatos em diferentes regiões de um dente restaurado com diferentes tipos de pinos metálicos. Foram usados alvéolos (regiões anterior e posterior) de uma mandibula e um dente unirradicular. Imagens de tomografia computadorizada de feixe cônico do dente sem pino metálico intracanal e com pinos de cobalto-cromo $(\mathrm{Co}-\mathrm{Cr})$, níquel-cromo $(\mathrm{Ni}-\mathrm{Cr})$ ou prata-paládio $(\mathrm{Ag}-\mathrm{Pd})$ foram individualmente obtidas, com 2 condições de FRA: desativada e ativada. Em uma reconstrução axial, linhas de interesse (LOIs) foram definidas ao redor do canal: 4 em direções oblíquas (mésio-vestibular, disto-vestibular, mésio-lingual e disto-lingual) e 4 em direções ortogonais (mesial, distal, vestibular e lingual). A expressão dos artefatos de endurecimento do feixe foi determinada pelo cálculo da diferença na média dos valores de cinza (DMVC) entre os grupos experimental e controle para cada LOI. Não houve diferença significativa nos valores de DMVC entre as condições "sem FRA" e "com FRA" para nenhuma das LOIs, nem na região anterior nem na região posterior da mandibula $(p>0,05)$, para os grupos $\mathrm{Ni}-\mathrm{Cr}$ e Co-Cr. Para o $\mathrm{Ag}-\mathrm{Pd}$, diferenças significativas nos valores de DMVC foram observadas entre "sem FRA" e "com FRA" para a maioria das LOIs $(p<0,05)$, principalmente nas direções oblíquas na região anterior, e na direção mesio-distal na região posterior. A FRA atuou principalmente em artefatos hipodensos (DMVC negativos). A eficácia da FRA disponivel no aparelho de TCFC OP300 variou de acordo com o material do pino testado. Ela foi efetiva na redução da expressão de artefatos originados por pinos de $\mathrm{Ag}-\mathrm{Pd}$, principalmente nas regiões do dente afetadas por artefatos hipodensos, independentemente da região mandibular.

\section{References}

1. Scarfe WC, Farman AG, Sukovic P. Clinical applications of cone-beam computed tomography in dental practice. J Can Dent Assoc 2006;72:75-80.

2. Ferreira LM, Visconti MA, Nascimento HA, Dallemolle RR, Ambrosano GM, Freitas DQ. Influence of CBCT enhancement filters on diagnosis of vertical root fractures: a simulation study in endodontically treated teeth with and without intracanal posts. Dentomaxillofac Radiol 2015;44:20140352.

3. Wanderley VA, Freitas DQ, Haiter-Neto F, Oliveira ML. Influence of Tooth Orientation on the Detection of Vertical Root Fracture in Cone-beam Computed Tomography. J Endod 2018;44:1168-1172.

4. Neves FS, Freitas DQ, Campos PS, Ekestubbe A, Lofthag-Hansen S. Evaluation of cone-beam computed tomography in the diagnosis of vertical root fractures: the influence of imaging modes and root canal materials. J Endod 2014;40:1530-1536.

5. Gaêta-Araujo H, Silva de Souza GQ, Freitas DQ, de Oliveira-Santos C. Optimization of Tube Current in Conebeam Computed Tomography for the Detection of Vertical Root Fractures with Different Intracanal Materials. J Endod 2017:43:1668-1673.

6. likubo M, Osano T, Sano T, Katsumata A, Ariji E, Kobayashi K, Sasano T, Wakoh M, Seki K, Kojima I, Sakamoto $M$. Root canal filling materials spread pattern mimicking root fractures in dental CBCT images. Oral Surg Oral Med Oral Pathol Oral Radiol 2015;120:521-527.

7. Fontenele RC, Farias Gomes A, Nejaim Y, Freitas DQ. Do the tube current and metal artifact reduction influence the diagnosis of vertical root fracture in a tooth positioned in the vicinity of a zirconium implant? A CBCT study. Clin Oral Investig 2021;25:2229-2235.

8. Fontenele RC, Farias Gomes A, Rosado LPL, Neves FS, Freitas DQ. Mapping the expression of beam hardening artefacts produced by metal posts positioned in different regions of the dental arch. Clin Oral Investig 2021;25:571-579.

9. Pinto MGO, Rabelo KA, Sousa Melo SL, Campos PSF, Oliveira LSAF, Bento PM, Melo DP. Influence of exposure parameters on the detection of simulated root fractures in the presence of various intracanal materials. Int Endod J 2017;50:586-594.

10. Queiroz PM, Oliveira ML, Groppo FC, Haiter-Neto F, Freitas DQ. Evaluation of metal artefact reduction in conebeam computed tomography images of different dental materials. Clin Oral Investig 2018;22:419-423.

11. Gaêta-Araujo H, Nascimento EHL, Fontenele RC, Mancini AXM, Freitas DQ, Oliveira-Santos C. Magnitude of beam-hardening artifacts produced by gutta-percha and metal posts on cone-beam computed tomography with varying tube current. Imaging Sci Dent 2020;50:1-7.

12. Freitas DQ, Fontenele RC, Nascimento EHL, Vasconcelos TV, Noujeim M. Influence of acquisition parameters on the magnitude of cone beam computed tomography artifacts. Dentomaxillofac Radiol 2018;47:20180151. 
13. Bechara B, Alex McMahan C, Moore WS, Noujeim M, Teixeira FB, Geha H. Cone beam CT scans with and without artefact reduction in root fracture detection of endodontically treated teeth. Dentomaxillofac Radiol 2013;42:20120245.

14. Bezerra IS, Neves FS, Vasconcelos TV, Ambrosano GM, Freitas DQ. Influence of the artefact reduction algorithm of Picasso Trio CBCT system on the diagnosis of vertical root fractures in teeth with metal posts. Dentomaxillofac Radiol 2015;44:20140428.

15. de-Azevedo-Vaz SL, Peyneau PD, Ramirez-Sotelo LR, Vasconcelos KdeF, Campos PS, Haiter-Neto F. Efficacy of a cone beam computed tomography metal artifact reduction algorithm for the detection of peri-implant fenestrations and dehiscences. Oral Surg Oral Med Oral Pathol Oral Radiol 2016;121:550-556.

16. Costa ED, Brasil DM, Queiroz PM, Verner FS, Junqueira RB, Freitas DO. Use of the metal artefact reduction tool in the identification of fractured endodontic instruments in cone-beam computed tomography. Int Endod J 2020;53:506-512.

17. Queiroz PM, Santaella GM, da Paz TD, Freitas DO. Evaluation of a metal artefact reduction tool on different positions of a metal object in the FOV. Dentomaxillofac Radiol 2017;46:20160366.

18. Vasconcelos KF, Codari M, Queiroz PM, Nicolielo LFP, Freitas DQ, Sforza C, Jacobs R, Haiter-Neto F. The performance of metal artifact reduction algorithms in cone beam computed tomography images considering the effects of materials, metal positions, and fields of view. Oral Surg Oral Med Oral Pathol Oral Radiol 2019;127:71-76.

19. Nascimento EHL, Fontenele RC, Santaella GM, Freitas DO. Difference in the artefacts production and the performance of the metal artefact reduction (MAR) tool between the buccal and lingual cortical plates adjacent to zirconium dental implant. Dentomaxillofac Radiol 2019;48:20190058.

20. Cicchetti DV. Guidelines, criteria, and rules of thumb for evaluating normed and standardized assessment instruments in psychology. Psychol Assess 1994;6:284-290.

21. de Rezende Barbosa GL, Sousa Melo SL, Alencar PN, Nascimento MC, Almeida SM. Performance of an artefact reduction algorithm in the diagnosis of in vitro vertical root fracture in four different root filling conditions on CBCT images. Int Endod J 2016;49:500-508.

22. Shaker IS, Mohamed NS, Abdelsamad AM. Diagnostic accuracy of cone beam computed tomography with and without metal artifact reduction algorithm in detection of vertical root fractures of teeth with metallic posts. J Med Radiol Pathol Surg 2017:4:9-12.

23. Tofangchiha $M$, Adel $M$, Tavakolian $E$, Ghaffari $P$, Jabbarian $R$. The effect of metal artifacts reduction algorithm on diagnostic accuracy of vertical root fracture by cone beam computed tomography, an in vitro study. Sch J Dent Sci 2017;4:115-120.

24. Dalili Kajan Z, Taramsari M, Khosravi Fard N, Khaksari F, Moghasem Hamidi F. The Efficacy of Metal Artifact Reduction Mode in Cone-Beam Computed Tomography Images on Diagnostic Accuracy of Root Fractures in Teeth with Intracanal Posts. Iran Endod J 2018;13:47-53.

25. Nikbin A, Dalili Kajan Z, Taramsari M, Khosravifard N. Effect of object position in the field of view and application of a metal artifact reduction algorithm on the detection of vertical root fractures on cone-beam computed tomography scans: An in vitro study. Imaging Sci Dent 2018;48:245-254.

26. Vanderstuyft T, Tarce M, Sanaan B, Jacobs R, de Faria Vasconcelos K, Quirynen M. Inaccuracy of buccal bone thickness estimation on cone-beam CT due to implant blooming: An ex-vivo study. J Clin Periodontol 2019;46:1134-1143.

27. Mauad LQ, Doriguêtto PVT, Almeida D, Fardim KAC, Machado AH, Devito KL. Quantitative assessment of artefacts and identification of gaps in prosthetic crowns: a comparative in vitro study between periapical radiography and CBCT images. Dentomaxillofac Radiol 2021;50:20200134.

28. Gaêta-Araujo $H$, Nascimento EHL, Oliveira-Santos N, Pinheiro MCR, Coelho-Silva F, Oliveira-Santos C. Influence of adjacent teeth restored with metal posts in the detection of simulated internal root resorption using CBCT. Int Endod J. 2020;53:1299-1306.

29. de-Azevedo-Vaz SL, Araujo-Siqueira C, Carneiro VC, Oliveira ML, Azeredo RA. Misfit detection in implantsupported prostheses of different compositions by periapical radiography and cone beam computed tomography: An in vitro study. J Prosthet Dent 2020:S0022-3913(20)30299-7.

30. Ramos Brito AC, Verner FS, Junqueira RB, Yamasaki MC, Queiroz PM, Freitas DQ, Oliveira-Santos C. Detection of Fractured Endodontic Instruments in Root Canals: Comparison between Different Digital Radiography Systems and Cone-beam Computed Tomography. J Endod 2017;43:544-549.

31. Rabelo KA, Cavalcanti YW, de Oliveira Pinto MG, Sousa Melo SL, Campos PSF, de Andrade Freitas Oliveira LS, de Melo DP. Quantitative assessment of image artifacts from root filling materials on CBCT scans made using several exposure parameters. Imaging Sci Dent 2017;47:189-197.

32. Lira de Farias Freitas AP, Cavalcanti YW, Costa FCM, Peixoto LR, Maia AMA, Rovaris K, Bento PM, Melo DP. Assessment of artefacts produced by metal posts on CBCT images. Int Endod J 2019;52:223-236. 
33. SedentexCT Guidelines. Radiation Protection 172. Cone beam CT for dental and maxillofacial radiology: evidence-based guidelines [Internet]. Available from: http://www.sedentexct.eu/files/radiation protection 172.pdf. (updated 2020 Sep 01).

34. Patel S, Brown J, Semper M, Abella F, Mannocci F. European Society of Endodontology position statement: Use of cone beam computed tomography in Endodontics: European Society of Endodontology (ESE) developed by. Int Endod J 2019;52:1675-1678.

35. Freitas DQ, Vasconcelos TV, Noujeim M. Diagnosis of vertical root fracture in teeth close and distant to implant: an in vitro study to assess the influence of artifacts produced in cone beam computed tomography. Clin Oral Investig 2019;23:1263-1270.

36. Hassan B, Couto Souza $P$, Jacobs R, de Azambuja Berti S, van der Stelt P. Influence of scanning and reconstruction parameters on quality of three-dimensional surface models of the dental arches from cone beam computed tomography. Clin Oral Investig 2010;14:303-310.

Received: $14 / 01 / 2021$

Accepted: 08/05/2021 